\title{
Kinetics of $\mathrm{Ge}_{20} \mathrm{Se}_{80-x} \mathrm{As}_{x}(x=0,5,10,15$ and 20) in glass transition region
}

\author{
KEDAR SINGH and N S SAXENA* \\ Department of Physics, University of Rajasthan, Jaipur 302 004, India
}

MS received 25 October 2002; revised 19 April 2003

\begin{abstract}
The results of differential scanning calorimetric (DSC) measurements on $\mathrm{Ge}_{20} \mathrm{Se}_{80-x} \mathrm{As}_{x}(x=\mathbf{0}, 5$, 10, 15 and 20) system with the specific aim of investigating the effect of heating rate and composition on glass transition temperature have been discussed. The results indicate that the glass transition temperature $\left(T_{\mathrm{g}}\right)$ is dependent both on the heating rate and composition. The glass transition activation energy $\left(E_{t}\right)$ and heat absorbed in glass transition region $(\Delta H)$ are higher for $\mathrm{Ge}_{20} \mathrm{Se}_{65} \mathrm{As}_{15}$ as compared to the values of other compositions of arsenic. An effort has also been made to develop an empirical model for the composition dependence of $\Delta H$. A good agreement has been observed between the experimental values and the results of model calculation.
\end{abstract}

Keywords. Glass transition temperature; activation energy; heat absorbed; composition dependence.

\section{Introduction}

Great attention has been given to chalcogenide glasses in recent years, mainly due to their wide range of applications in solid state devices both in scientific and technological fields (Seddon 1995). These glasses exhibit unique IR transmission and electrical properties that make them useful for several applications such as threshold switching, memory switching, inorganic photoreceptors, IR transmission and detection through lenses and optical wave-guides e.g. in welding and surgery (Nishi et al 1992). Especially amorphous chalcogenide alloys exhibit the property of reversible transformation. This property makes these systems very useful in optical memory.

Glasses are amorphous (Elliot 1990) in nature, i.e. they form a disordered and metastable structure. It is possible to change continuously the elemental ratios in glass compounds. Due to the lack of translational symmetry, the properties of such substances strongly depend on the character and concentration of chemical bonds, which hold the atoms together in the glassy network. Since the variation of glass transition temperature $\left(T_{\mathrm{g}}\right)$ with heating rate (Moyniyan et al 1974; Joshi et al 1994) and composition (Philips and Thorpe 1985) is of sufficient importance for amorphous materials, this paper reports the differential scanning calorimetric (DSC) measurements on $\mathrm{Ge}_{20} \mathrm{Se}_{80-x} \mathrm{As}_{x}(x=0,5,10,15$ and 20) in the glass transition region. The results indicate that the glass transition temperature $\left(T_{\mathrm{g}}\right)$ and heat absorbed $(\Delta H)$ in glass transition region, both are dependent on heating rate as

*Author for correspondence well as composition. An effort has also been made to compare theoretical results of $T_{\mathrm{g}}$ at different heating rates and compositions with the experimentally measured values of $T_{\mathrm{g}}$. Besides, experimental values of heat absorbed in the glass transition region have been compared with the values obtained through an empirical model.

\section{Material preparation}

High purity (99.999\%) Se, Ge and As in appropriate atomic percent proportions were weighed into a quartz glass ampoule (length, $5 \mathrm{~cm}$ and internal diameter, $8 \mathrm{~mm}$ ). The contents of the ampoule were sealed in a vacuum $10^{-5}$ Torr and heated at a rate of $3-4^{\circ} \mathrm{C} / \mathrm{min}$ in a rotary furnace at a temperature of $800^{\circ} \mathrm{C}$ for $9-10 \mathrm{~h}$ to ensure homogeneity. The molten samples were then rapidly quenched in ice cooled water. The glassy nature of alloys was ascertained by X-ray diffraction.

\section{Experimental}

A convenient way of monitoring glass transition phenomenon is by means of DSC, in which the sample is heated at a constant rate and the changes in heat flow with respect to an empty reference pan are measured. Glass transition temperature $\left(T_{\mathrm{g}}\right)$ has been identified as the temperature where the base line of DSC exhibits a small shift in the endothermic direction.

Thermal behaviour of five samples of the system $\mathrm{Ge}_{20} \mathrm{Se}_{80-x} \mathrm{As}_{x}(x=0,5,10,15$ and 20$)$ has been investigated using a Rigaku DSC (model 8230B). The temperature precision of this equipment is $\pm 0 \cdot 1 \mathrm{~K}$ with an 
average standard error of about $1 \mathrm{~K}$ in the measured values.

\section{Results and discussion}

Differential scanning calorimetry (DSC) has been employed to obtain the thermograms of $\mathrm{Ge}_{20} \mathrm{Se}_{x-80} \mathrm{As}_{x}(x=0,5,10$, 15 and 20) chalcogenide glasses at different heating rates. From these DSC thermograms glass transition temperatures have been determined for each composition at the heating rates of $10,12,15,17$ and $20 \mathrm{~K} / \mathrm{min}$. The values of glass transition temperatures have been plotted with composition of arsenic in the glass at 10,15 and $20 \mathrm{~K} /$ min heating rates in figure 1 . Theoretical values of glass transition temperature corresponding to composition of As at each heating rate have also been calculated using Gibb's-Dimarzio equation (Sreeram et al 1991)

$$
T_{\mathrm{g}}=\frac{T_{0}}{[1-\beta(\langle r\rangle-2)]},
$$

where $T_{0}$ is glass transition temperature of the non-crosslinked parent chain and taken from table 1 for the glass. $\beta$ is a constant and taken as $0 \cdot 16$ for the present glass. $\langle r\rangle$ is the average coordination number of $\mathrm{Ge}_{20} \mathrm{Se}_{x-80} \mathrm{As}_{x}$ $(x=0,5,10,15$ and 20) and is calculated by mathematical formula of Swiler et al (1990). Theoretically calculated values have also been plotted in figure 1, for the sake of comparison with the experimental values. An excellent agreement has been observed between the experimental and theoretical values of the glass transition temperature $\left(T_{\mathrm{g}}\right)$ for each heating rate. Both, experimental as well as theoretical results of $T_{\mathrm{g}}$ at each heating rate

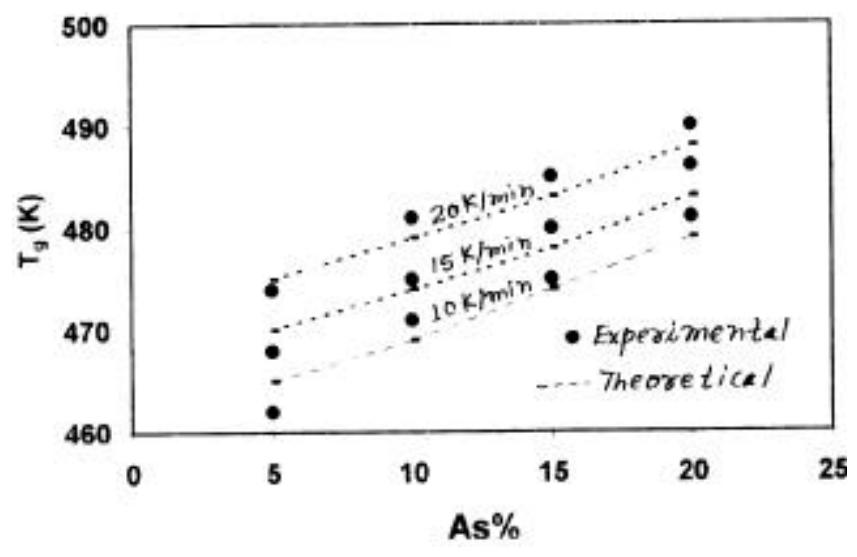

Figure 1. The variation of $T_{\mathrm{g}}$ [experimental $(\bullet)$, theoretical $(.)$.$] with compositions at different heating rates.$ show that $T_{\mathrm{g}}$ increases almost linearly with the composition of As in the chalcogenide glass. This increasing trend of $T_{\mathrm{g}}$ with As atomic weight percentage is explained in the following way. When arsenic is added to the glass at the cost of selenium, it enters into the $(\mathrm{Se})_{n}$ chains connecting the tetrahedral units of $\mathrm{Ge}$ and also crosslinks the chains.

This crosslinking of the chains by the addition of As further strengthens As-Se bond structure and increases the chain lengths and therefore accounts for the increase of $T_{\mathrm{g}}$ with increase of As concentration in the glass.

Figure 2 shows the heating rate dependence of glass transition temperature $\left(T_{\mathrm{g}}\right)$ for 0,5 and 10 atomic wt. percentages of arsenic. Theoretical values of $T_{\mathrm{g}}$ have been calculated using the empirical relation given as (Maharajan et al 2000)

$$
T_{\mathrm{g}}=A+B \ln \alpha,
$$

where $A$ and $B$ are the empirical constants, and $\alpha$ the heating rate. Values of $A$ are $401 \mathrm{~K}, 420 \mathrm{~K}$ and $460 \mathrm{~K}$, and of $B$ are $13.18 \mathrm{~min}, 17.5 \mathrm{~min}$ and $14.58 \mathrm{~min}$ for $\mathrm{Ge}_{20} \mathrm{Se}_{80}, \mathrm{Ge}_{20} \mathrm{Se}_{75} \mathrm{As}_{5}$ and $\mathrm{Ge}_{20} \mathrm{Se}_{70} \mathrm{As}_{10}$, respectively.

Values obtained from the above relation have also been shown in the same figure 2, for comparison with the experimental values. It is observed that $T_{\mathrm{g}}$ varies linearly with the heating rate. It is well known (Agrawal et al 1991) that the dependence of $T_{\mathrm{g}}$ in chalcogenide glasses is interpreted in terms of thermal relaxation phenomena, in such a kinetic interpretation, the enthalpy is central to any adequate understanding of its structure and properties. Theoretically, $T_{\mathrm{g}}$ is defined as the temperature at which the relaxation time, $\tau$, becomes equal to an experimental time of observation, $\tau_{\mathrm{obs}}$. At the same time, $T_{\mathrm{g}}$ varies inversely as the relaxation time. With increase of heating rate, $\tau_{\mathrm{obs}}$ decreases and hence the glass transition temperature increases. The glass transition activation energy, $E_{\mathrm{t}}$, is the amount of energy, which is absorbed by a group of atoms in the glassy region, so that a jump from one metastable state to another is possible. This activation energy is involved in the molecular motion and rearrangement of atoms around the glass transition temperature. Glass transition activation energy has been evaluated (Mahadevan et al 1986; Afify 1991) using Kissinger peak shift method for glass transition region. $E_{\mathrm{t}}$ is calculated by peak glass transition temperature using Kissinger peak shift method and $E_{\mathrm{g}}$ is calculated by glass transition temperature using Ozawa method. The justification of applying this method for the evaluation of the glass transition activation energy comes from the shifting of glass transition peaks at different heating rates similar to crystalliza-

Table 1. Glass transition temperature $\left(T_{\mathrm{g}}\right)$ of $\mathrm{Ge}_{20} \mathrm{Se}_{80}$ (non-crosslinked) glass at different heating rates.

\begin{tabular}{lccccc}
\hline Heating rate $(\alpha)$ & $10 \mathrm{~K} / \mathrm{min}$ & $12 \mathrm{~K} / \mathrm{min}$ & $15 \mathrm{~K} / \mathrm{min}$ & $17 \mathrm{~K} / \mathrm{min}$ & $20 \mathrm{~K} / \mathrm{min}$ \\
\hline Glass transition temp. $\left(T_{\mathrm{g}}\right)$ & $432 \mathrm{~K}$ & $436 \mathrm{~K}$ & $437.5 \mathrm{~K}$ & $439 \mathrm{~K}$ & $441 \mathrm{~K}$ \\
\hline
\end{tabular}


tion peaks. Values of $E_{\mathrm{t}}$ have been plotted for different compositions of arsenic (As) in figure 3. Also Ozawa's (1970) method has been used on similar lines as for crystallization, to determine the glass transition activation, $E_{\mathrm{g}}$, with the help of variation in actual glass transition temperature $\left(T_{\mathrm{g}}\right)$ with heating rates. Values of $E_{\mathrm{g}}$ at different compositions of arsenic have also been plotted in figure 3 . It is noted from figure 3 that the variation of glass transition activation energy, $E_{\mathrm{t}}$, and $E_{\mathrm{g}}$, with arsenic composition, is in close agreement. A comparison of two curves $\left(E_{\mathrm{g}}, E_{\mathrm{t}}\right)$ in figure 3 reveals that the most stable glass $\mathrm{Ge}_{20} \mathrm{As}_{15} \mathrm{Se}_{65}$ has the highest activation energy (Maharajan et al 2000) as calculated from both Ozawa and Kissinger methods.

Similar trend has been observed for the energy absorbed in glass transition region $(\Delta H)$ with composition of arse-

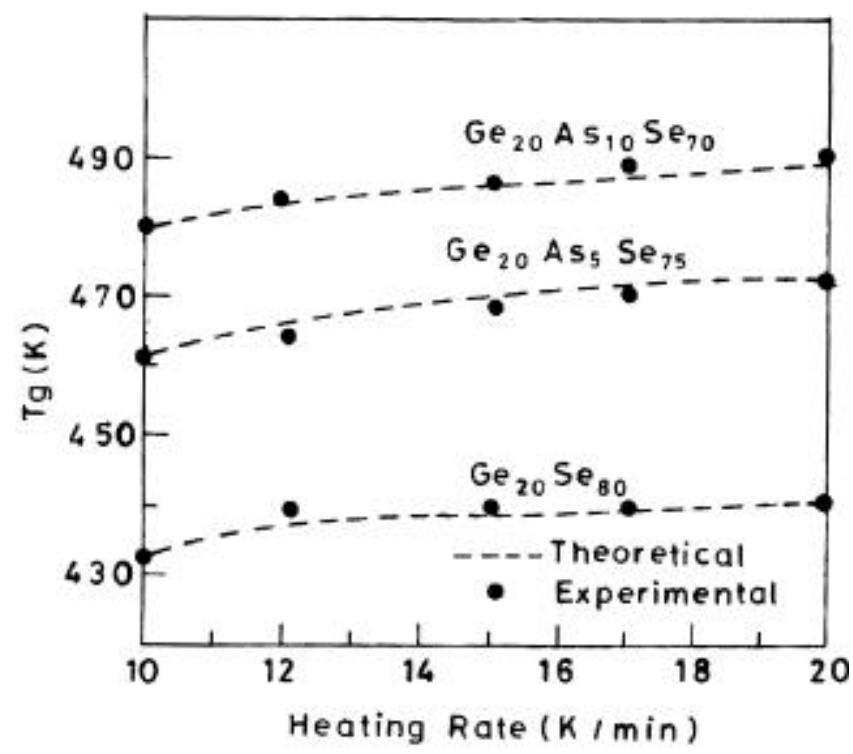

Figure 2. The variation of $T_{\mathrm{g}}$ [experimental $(\bullet)$, theoretical $(.)$.$] with heating rates at different compositions.$

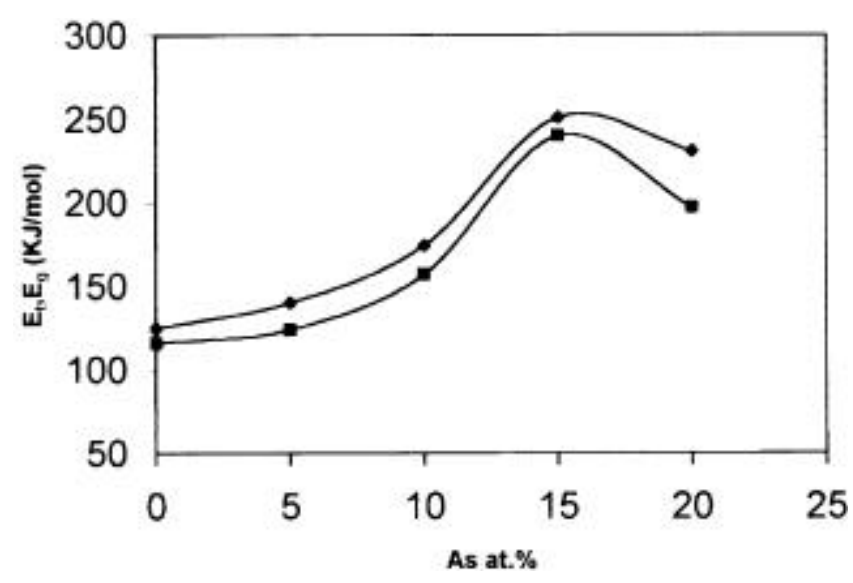

Figure 3. Glass transition activation, $E_{\mathrm{t}}(-\mathbf{-})$ by Kissinger method and $E_{\mathrm{g}}(\bullet-)$ by Ozawa method vs As percentage. nic in the glass at each heating rate $(\alpha)$. Values of $\Delta H$ for each composition have been calculated by calculating the area between endothermic curve and the base line of the DSC thermogram at fixed heating rate corresponding to each composition using an equation

$$
\Delta H=k A / m,
$$

where $k$ is the instrument constant, which is found to be $1 \cdot 5, A$ the area of the curve in endothermic region and $m$ the mass of sample. The variation of $\Delta H$ with composition $(x)$ of arsenic at each heating rate can be empirically depicted by a relationship

$$
\Delta H=A^{\prime}(x)^{3 / 2} e^{B^{\prime}(x-0 \cdot 15)}+C^{\prime} \alpha e^{\alpha},
$$

where $A^{\prime}, B^{\prime}$ and $C^{\prime}$ are constants and are calculated from the given experimental conditions. $\alpha$ is the heating rate and $x$ the composition fraction of arsenic in the $\mathrm{Ge}_{20} \mathrm{Se}_{80-x} \mathrm{As}_{x}$ ( $x=0,5,10,15$ and 20) chalcogenide glass. The values obtained from this empirical relation have been plotted in figure 4 together with the experimental values. It has been observed that energy absorbed in glass transition region increases with the arsenic concentration in the glass. It becomes maximum for $x=15$, where the system is most stable as also predicted from the viscosity and

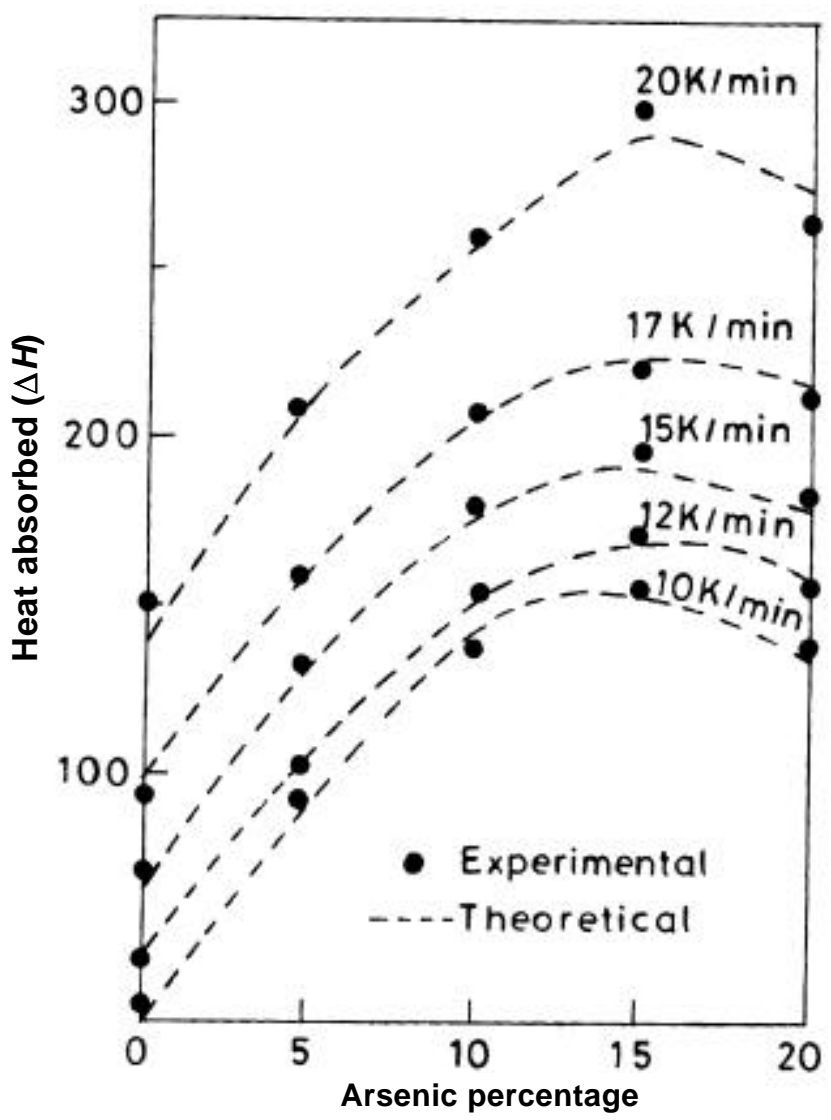

Figure 4. Experimental and theoretical energy absorbed in glass transition region vs As percentage. 
density measurements of these glasses (Myers and Felty 1967) and for further values of $x$ the energy absorbed again decreases. Experimental values are also in good agreement with the values calculated by empirical equation and depict the true behaviour of the glassy system, when heated at different heating rates. It is interesting to note that for these samples glass transition temperature $\left(T_{\mathrm{g}}\right)$ is $>150^{\circ} \mathrm{C}$ and is potentially available for various applications. Non-crystallization of these glasses is due to the property of arsenic being particularly effective in providing thermal stability and resistance to crystallization (Myers and Felty 1967).

\section{Conclusions}

The study of kinetics of Ge-As-Se system in the glass transition region shows that $\mathrm{Ge}_{20} \mathrm{As}_{15} \mathrm{Se}_{65}$ is most stable. At this concentration of arsenic the material behaves as an anti-crystalline material indicating its highest suitability for a low index application.

\section{Acknowledgements}

We are thankful to Mr R K Mangal for providing help in theoretical modeling. Financial support from the University of Rajasthan, Jaipur, is gratefully acknowledged.

\section{References}

Afify N 1991 J. Non-Cryst. Solids 128279

Agrawal P, Goel S, Rai J P S and Kumar A 1991 Phys. Status Solidi (a)127 363

Elliot S R 1990 Physics of amorphous materials (New York: John Wiley \& Sons, Inc) p. 35

Joshi S R, Pratap A, Saxena N S and Saksena M P 1994 J. Mater. Sci. Lett. 1377

Mahadevan S, Giridhar A and Singh A K 1986 J. Non-Cryst. Solids $\mathbf{8 8} 11$

Maharajan N B, Saxena N S, Bhandari D, Imran M A and Paudyyal D D 2000 Bull. Mater. Sci. 23369

Maharajan N B, Bhandari D, Saxena N S, Paudyal D D and Husain M 2000 Phys. Status Solidi (a)178 663

Moyniyan T C, Easteal A J, Walder J and Tucker J 1974 J. Phys. Chem. 782673

Myers M B and Felty E J 1967 Mater. Res. Bull. 2535

Nishi J, Morimoto S, Inagawa I, Iizuka R, Yamashita $\mathrm{T}$ and Yamagishi T 1992 J. Non-Cryst. Solids 140199

Ozawa T 1970 J. Therm. Anal. 2301

Philips J C and Thorpe M F 1985 Solid State Commun. 53 699

Seddon A B 1995 J. Non-Cryst. Solids 18444

Sreeram A N, Swiler D R and Varshneya A K 1991 J. NonCryst. Solids 127287

Swiler D R, Varshneya A K and Callihan R M 1990 J. NonCryst. Solids 125250 